International Journal of Current Advanced Research

ISSN: O: 2319-6475, ISSN: P: 2319 - 6505, Impact Factor: SJIF: 5.995

Available Online at www.journalijcar.org

Volume 6; Issue 3; March 2017; Page No. 2919-2922

DOI: http://dx.doi.org/10.24327/ijcar.2017.2922.0142

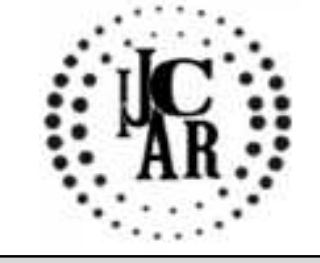

Research Article

\title{
PERFORATIONS IN ENDODONTICS
}

\section{Syed Shihaab S and Subash Sharma}

Department of Conservative and Endodontics, Saveetha Dental College

\begin{tabular}{l}
\hline A R T I C L E I N F O \\
Article History: \\
Received $20^{\text {th }}$ December, 2016 \\
Received in revised form $24^{\text {th }}$ January, 2017 \\
Accepted $4^{\text {th }}$ February, 2017 \\
Published online $28^{\text {th }}$ March, 2017
\end{tabular}

Key words:

Perforations, Endodontic Procedure

\begin{abstract}
A B S T R A C T
Aim: To determine the various causes of perforations and how to overcome problems related to perforation in endodontic procedure

Objective: The objective of this study is to have a detailed idea on perforations in endodontics

Back Ground: Prime objective of an access cavity is to provide straight line pathway to the apical foramen. Perforation occurs due to excess removal of tooth structure or may occur during attempts to locate canals. If straight line access is not attained there is high risk for intracanal accidents. Perforation need to be recognised early to avoid subsequent damage to periodontal tissues with instruments.

Reason: This study is done to have a detailed idea on causes of perforations of root canal and problems related to it. With this study we can have a clear idea on perforations in endodontics.
\end{abstract}

Copyright $₫ 2017$ Syed Shihaab S and Subash Sharma. This is an open access article distributed under the Creative Commons Attribution License, which permits unrestricted use, distribution, and reproduction in any medium, provided the original work is properly cited.

\section{INTRODUCTION}

Canal perforation can be identified by blood in the cavity or patients complains of taste of $\mathrm{NaOcl}$. Initially site of perforation must be found, the floor of the preparation is cleansed, the bleeding stooped and MTA is then applied. Root perforations occurs due to three errors creating a ledge and persisting until a perforation develop.

A perforation is a communication between the root canal system and the supporting tissues of the tooth or oral cavity.1,2 Perforations may be iatrogenic, resorptive or carious in origin. Iatrogenic root perforations are the second most common reason for endodontic failure.3,4 The frequency of iatrogenic root perforations has been reported to range from $3 \%$ to $10 \% .3,4,5$ This article will focus on iatrogenic perforations and their avoidance.

Perforations in endodontics can occur during:

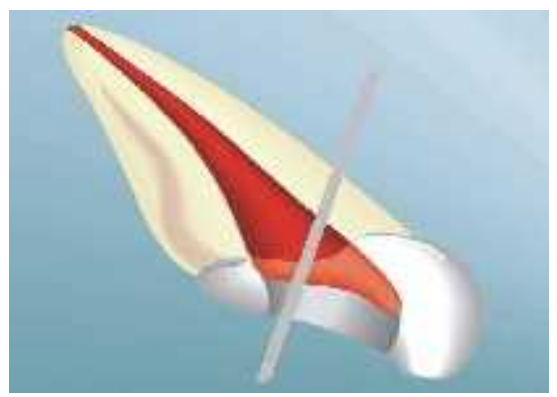

\section{*Corresponding author: Syed Shihaab S}

Department of Conservative and Endodontics, Saveetha Dental College
- Access preparation.

- Canal location and identification.

- Root canal instrumentation.

- Post space preparation.

\section{Classification}

Perforations are classified as

1. Root perforations- cervical perforations

- Midroot perforations

- Apical perforations

2. Furcal perforations.

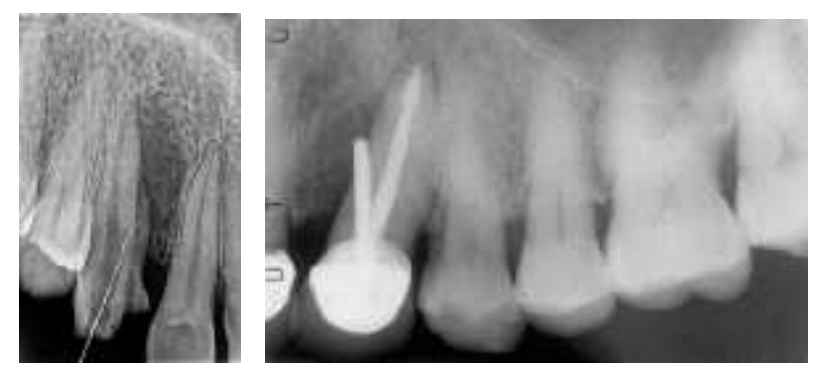

\section{Cervical Perforation}

Cervical perforations occur when large instrument is used to widen the canal orifice, like in case of gates glidden and peeso drill. It is indicated with the presence of blood in the canal. ${ }^{(6)}$

\section{Midroot Perforation}

Midroot perforation is caused by zipping, it usually occurs in the distal wall of a curved mesial root of mandibular molar. 
It can be identified with presence of blood within the root canal. $^{(6)}$

\section{Apical Perforation}

Apical perforation occurs due to overzealous instrumentation. it can be determined with paper points that gives bloody appearance. $^{(6)}$

\section{Etiology}

Endodontic perforations occurs due to the following reasons ${ }^{(5)}$

- If straight line access is not achieved

- Searching canals through an unprepared access cavity

- Access through a small or flattened pulp chamber in a multirooted tooth

- Failure to direct the bur parallel to the long axis of the tooth.

- Access through a cast crown often is not aligned in the long axis of the tooth.

Perforation can be recognised by sudden pain, sudden haemorrhage, radiograph, apex locator, taste of $\mathrm{NaOcl}$ during irrigation

\section{Repair Materials}

Ideal repair material for furcal and root perforation should be antimicrobial, non-toxic, non-absorbable, radiopaque, noncacinogenic and promote osteogenesis and cementogenesis Chloroform rosin and GP cones with phosphate cement first introduced in 1967. Later ZOE was also used to repair perforations. Since ZOE causes chronic inflammatory response it was not widely used. Calcium hydroxide was introduced later for positive attachment response and separate hard tissue barrier to form. Few studies revealed that use of cavit gave favourable responses among 89 percent of individuals. Super EBA introduced in 1985 to restore perforations. It provides poorer seal than amalgam in root perforation. It is used as retro filling material. GIC were introduced in 1990 to repair lateral root perforations. GIC provoked inflammatory response that was less severe than GP .Later MTA was introduced in 1990 for furcal perforation defects.

\section{Mta-Mineral Trioxide Aggregate}

MTA consists of calcium and phosphorous ions. It comprises of fine hydrophilic particles of tricalcium silicate, tricalcium laminate, tricalcium oxide. Also contains small amount of mineral oxides. Bismuth oxide powder is then added to make the aggregate radiopaque. PH of MTA is 12.5. It has low solubility and low compressive strength, hence it should not be placed in functional areas

Torabinejad and colleagues found no marginal gaps in root end fillings with MTA, while they found gaps ranging from 3.8 to 14.9 microns with amalgam, super EBA and IRM. In another studies Torabinejad and colleagues found that MTA leaked significantly less than amalgam and super EBA when placed in $3 \mathrm{~mm}$ root end preparations ${ }^{(7)}$. Torabinejad and colleagues on the effects of blood on root end fillings, MTA leaked significantly less than amalgam and IRM and super EBA. Bates and colleagues used a fluid filtration device to test the sealing properties of MTA super EBA nd amalgam, it was found that MTA has superior sealing properties when compared to others.

$\mathrm{Wu}$ and colleagues found that the seal created with MT in root end fillings lats for at least a year ${ }^{(8)}$. Torabinejad and colleagues evaluated coronal microleakage of bacteria in the canals of single rooted teeth that had $3 \mathrm{~mm}$ root end filling of either MTA, amalgam, super EBA, they saw no leakage in any MTA filled tooth at the end of the study. Tang and colleagues showed that MTA was superior to amalgam and IRM. lee and colleagues reported that in the lateral root perforations, MTA leaked significantly less than IRM nd amalgam.

Biocompatibility of MTA was studied by various authors and found it to be nonmutagenic, less cytotoxic, that allowed cementum overgrowth ${ }^{(9)}$. MTA is not just an inert material but may actively promote hard tissue formation.

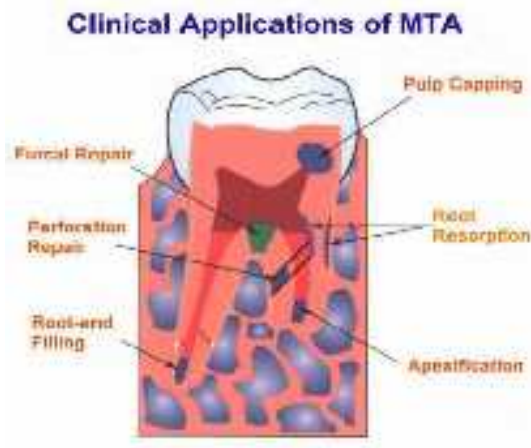

\section{Antimicrobial Property of Mta}

MTA was found to have an antibacterial effect but no effect on any of the strict anaerobes. Torabinejad and colleagues found that there is less inflammatory response and better dentin bridge formation with MTA when direct pulp capping is done. Myers and colleagues evaluated MTA and Calcium hydroxide as ulp capping material in dogs and found that there is no statistically significant difference in pulpal status or dentin bridging between the two materials. Pitt ford concluded that MTA is more suitable for furcation repair than amalgam, especially if the repair is done immediately. Torabinejad and colleagues reported osseous repair furcation perforations repaired with MTA. ${ }^{(10)}$

\section{Calcium hydroxide}

Since its presentation by Herman in 1920's, it was utilized for an extensive variety of purposes in both traditionalist field and endodontics. It is a substance that is naturally perfect with pulpal and periodontal tissues. By piece calcium hydroxide comprises of a base glue and impetus glue.

Base glue comprises of 1-methyl trimethyl enedisalicylate, Calcium sulfate, Titanium dioxide, Calcium tungstate orbarium sulfate and Catalyst glue comprises of Calcium hydroxide, Zinc oxide, Zinc stearate, Ethylene toluene, Sulphonamide.

P Bogaerts et al., utilized calcium hydroxide as framework and Super EBA as the material for aperture repair. It prompt to great clinical outcomes with positive result ${ }^{[12]}$. In another review by Clovis Monteiro Bramante et al., examples dressed with calcium hydroxide glue in addition to iodoform for 
aperture repair demonstrated rot at the site of puncturing and distinctive levels of cementum hyperplasia ${ }^{[13]}$.

\section{Biodentine}

Biodentine is a calcium silicate-based bioactive material. It is a powder fluid framework, powder made out of Tri-calcium silicate, Di-calcium silicate, Calcium carbonate and oxide, Iron oxide, Zirconium oxide. Fluid comprise of Calcium chloride, Hydro solvent polymer.

It is anything but difficult to deal with attributable to its simplicity of control and a short setting time around 12 minutes, has high antacid $\mathrm{pH}$ and is a biocompatible material makes it a great material for puncturing repair ${ }^{[14,15]}$. In a review by Guneser et al.,, Biodentine demonstrated extensive execution as an aperture repair material even subsequent to being presented to different endodontic irrigants when contrasted with MTA ${ }^{[16]}$.

\section{Glass Ionomer Cement}

It is a powder fluid framework. Powder is made out of silica, alumina, aluminum fluoride, calcium fluoride, sodium fluoride, aluminum phosphate and fluid comprising of polyacrylic corrosive, tartaric corrosive and water. At the point when utilized as aperture repair material, Alhadainy and Himel observed that light-cured glass ionomer concrete showed a superior seal than amalgam or Cavit when utilized for furcation holes repair ${ }^{[17]}$. A resulting study proposed that light-cured glass ionomer concrete has better fixing capacity thought about than artificially cured glass ionomer bond ${ }^{[18]}$.

In another review, James et al., reasoned that there was no huge distinction in the mean degree of color spillage among the three gatherings that is light-cured glass ionomer bond, calcium phosphate concrete, or light-cured glass ionomer bond put over a Calcium Phosphate Cement grid when utilized for aperture repair ${ }^{[19]}$. General it is demonstrated that Glass Ionomer Cement displays a more noteworthy fixing potential than traditional materials because of its bond property.

\section{Management}

\section{Lateral root perforation}

- If the perforation is at or above the level of crestal bone, restorative treatment can be carried out.

- Perforation below the height of crestal bone in the coronal third of the root, the treatment goal is to position the apical portion of the defect above the crestal bone by orthodontic extrusion and crown lengthening. Internal repair by MTA is also possible. $^{(11)}$

\section{Direct Perforation}

The treatment would be immediate sealing using the suitable restorative material

\section{Stripping Perforation}

Results from excessive flaring with files or drills. Non surgical treatment by immediate sealing using MTA. And surgical treatment is hemisection, bicuspidization, root amputation.

\section{Factors Affecting the Prognosis}

- The location of the defect
- $\quad$ Size of the defect

- Presence or absence of periodontal communication to the defect

- The time between perforation and repair

- Sealing ability of the restorative material

- Accessibility for repair ${ }^{(11)}$

\section{CONCLUSION}

From this review we get a detailed idea about perforations seen in endodontics. Perforatons in common can be caused due to misangled Access preparation, while Canal location and identification, while root canal instrumentation and while post space preparation. From this review we can also have a good idea on the various material used for repair purpose of perforation. The various repair material are MTA, GIC, biodentine, calcium hydroxide, IRM, etc.

\section{Reference}

1. Alhadainy, H.A., Root perforation. A review of the literature. Oral Surgery Oral Medicine Oral Pathology, 1994; 78: 368 -374.

2. Fuss, Z., Trope, M., Root perforations: classification and treatment choices based on prognostic factors. Journal of Endodontics and Dental Traumatology, 1996; 12: 255 -264.

3. Seltzer, S., Bender, I.B., Smith, J., Freedman, I., Nazimov, H., Endodontic failures an analysis based on clinical, roentgenographic and histologic findings.

4. Ingle, J.I., Taintor, J.F., Endodontics, 3rd Ed., 1985, Lea \& Febiger.

5. Kerekes, K., Tronstad, L., Long-term results of endodontic treatment performed with a standardised technique. Journal of Endodontic, 1979; 5: 83 - 90

6. Anahita Gupta., International postdoctoral training program., Endodontic Errors

7. Beltes P, Zervas P, Lambrianidis T, Moylvdas I. In vitro study of the sealing ability of four retrograde filling materials. Endod Dent Traumatol 1988; 4: 8284.

8. Bondra D L, Hartwell G R, MacPherson M G, Portell F R. Leakage in vitro with IRM, high copper amalgam and EBA cements as retrofilling materials. $J$ Endodon 1989; 15: 157-160.

9. Torabinejad M, Watson T F, Pitt Ford T R. Sealing ability of Mineral Trioxide Aggregate when used as a root end filling material. J Endodon 1993; 19: 591-595.

10. Onynick J, Onynic T. A study of a new material for retrograde fillings. J Endodon1978; 4: 203-206.

11. S. Mohammed Saed ${ }^{1}$, M. P. Ashley ${ }^{2} \&$ J. Darcey ${ }^{3}$., Root perforations: aetiology, management strategies and outcomes. The hole truth. British Dental Journal 220, 171 - 180 (2016)

12. Bogaerts $P$. Treatment of root perforations with calcium hydroxide and Super EBA cement: a clinical report. Int Endod J. 1997;30:210-19. [PubMed]

13. Bramante CM, Berbert A. Root perforation dressed with calcium hydroxide or zinc oxide and eugenol. $J$ Endod. 1987;13(8):392-95. [PubMed]

14. Priyalakshmi S, Ranjan M. Review of Biodentine-a bioactive dentin substitute. IOSR journal of dental and medical sciences. 2014;13(1):13-7. 
15. Han L, Okiji T. Uptake of calcium and silicon released from calcium silicate-based endodontic materials into root canal dentine. Int Endod J. 2011;44:108187. [PubMed]

16. Guneser MB, Akbulut MB, Eldeniz AU. Effect of Various Endodontic Irrigants on the Push-out Bond Strength of Biodentine and Conventional Root Perforation Repair Materials. J Endod. 2013:39-3. 38084.[PubMed]
17. Alhadainy HA, Himel VT. Evaluation of the sealing ability of amalgam, cavit and glass ionomercementin the repair of furcation perforations. Oral surg. 1993; 75:362-66. [PubMed]

18. Alhadainy HA, Himel VT. Comparative study of the sealing ability of light cured versus chemically cured materials placed in furcation perforations. Oral surg. 1993; 76:338-42. [PubMed]

19. Chau JYM, Hutter JW, Mork TO, Nicoll BK. An invitro study of furcation perforation repair using calcium phosphate cement. J Endod. 1997;23(9):58892. [PubMed]

\section{How to cite this article:}

Syed Shihaab S and Subash Sharma (2017) ' Perforations In Endodontics', International Journal of Current Advanced Research, 06(03), pp. 2919-2922.

DOI: http://dx.doi.org/10.24327/ijcar.2017.2922.0142 